\title{
Respiratory illness in British schoolchildren and atmospheric smoke and sulphur dioxide 1973-7
}

\section{II: Longitudinal findings}

\author{
R. J. W. MELIA, C. du V. FLOREY, AND S. CHINN \\ From the Department of Community Medicine, St. Thomas's Hospital Medical School, London
}

SUMmARY A study was set up to investigate the effects of annual changes in the levels of atmospheric smoke and $\mathrm{SO}_{2}$ on changes in health from 1973 to 1977 in primary schoolchildren from 28 randomly selected areas of England and Scotland. Changes in health were measured by taking the change in number of respiratory conditions reported from one annual examination to the next. The number of areas with data on pollution in each period was $5,9,17$, and 14 respectively and within these areas the response rate varied from $65 \%$ to $74 \%$. Altogether $857,1436,2702$, and 2036 children respectively who were of white ethnic origin, aged 6 to 11 , and had complete data on sex, social class, and changes in health were studied in each period. In 1973-4 the levels of pollution were highest and showed the greatest decline. The greatest annual mean change in smoke was a decrease from 71.9 to $50.5 \mu \mathrm{g} / \mathrm{m}^{3}$ and in $\mathrm{SO}_{2}$ a decrease from 94.2 to $47.6 \mu \mathrm{g} / \mathrm{m}^{3}$. However, no relation was found between improvement in health and decreasing levels of pollution. In subsequent years, when the levels of pollution were lower and showed smaller changes, change in health was also unrelated to changes in pollution. Thus no evidence was found to suggest that the levels measured during the study were harmful to health.

In the past respiratory illness in primary schoolchildren has been associated with high levels of atmospheric smoke and sulphur dioxide $\left(\mathrm{SO}_{2}\right)$ in the United Kingdom. ${ }^{12}$ However, as the levels of these pollutants have been declining in recent years, ${ }^{3}$ a National Study of Air Pollution was conducted from 1973 to 1977 to investigate the effects of changes in low levels of pollution on respiratory illness in primary schoolchildren.

In cross-sectional analyses presented in the preceding paper ${ }^{4}$ the prevalence of respiratory illness was found to be higher in areas with high levels of smoke than in areas with low levels over the range of annual means 8.0 to $50.5 \mu \mathrm{g} / \mathrm{m}^{3}$. This range of levels was much lower than that at which effects from smoke on children's health have previously been reported. We suggested that an analysis of the effects of changes in the annual levels of pollution on changes in health might confirm whether low levels of smoke measured during the study were harmful to health.

\section{Methods}

POPULATION AND DATA COLLECTION

Details of the study population and method of data collection can be found in the accompanying paper. ${ }^{4}$ Briefly, children aged 6 to 11 who attended selected schools in 28 randomly selected areas of England and Scotland were studied annually by a self-administered questionnaire completed by each child's mother or guardian from 1973 to 1977. Fieldworkers from St. Thomas's Hospital visited 18 English areas during the summer and the remainder in the autumn to organise the fieldwork. Information was collected on the presence of cough, wheeze, and colds going to the chest, and the number of attacks of asthma and bronchitis experienced during the previous 12 months. Data were also obtained on socioeconomic and environmental characteristics of the children's homes. Smoke and $\mathrm{SO}_{2}$ were measured daily by the British Standard Smoke/ $\mathrm{SO}_{2}$ method ${ }^{5}$ at or near the children's schools in each area.

\section{MEASURE OF CHANGES IN HEALTH}

The longitudinal nature of the data needed to be taken into account. Korn and Whittemore ${ }^{6}$ have suggested that changes in health should be studied by examining changes experienced by individuals rather than the change in an average measure of health for groups. Certainly prevalence rates would have provided an insensitive measure of change in health as most children experienced no illness throughout the study.

In the cross-sectional analyses some interrelationship was found between the responses to the six respiratory questions and a simple count was made of the number of conditions reported for each child. Changes in health were studied by examining 
the proportion of children who experienced a decrease, no change, or an increase in number of conditions reported for the year between two examinations. Longer periods were not studied.

In the regression analyses which require a binary response the dependent variable, the number of categories of change in health, was reduced to two. An index of improvement in health was formed, based on the hypothesis that relatively more children in areas with declining levels of pollution than in other areas would experience a decrease rather than an increase in their number of conditions. A decrease and an increase in the number of conditions were the two response categories for the dependent variable; those children showing no change were omitted from the analysis.

MEASURE OF CHANGE IN POLLUTION

The mean levels of smoke and $\mathrm{SO}_{2}$ for the winter preceding the visit to each area were studied, because these levels of pollution tended to be higher and provided a wider separation between the areas than levels at other times of the year. In addition, winter means appeared to be associated with prevalence of respiratory illness in the cross-sectional analysis. The annual means and their changes showed high positive correlations with the winter means so the relation of the two measures of pollution to changes in health were very similar.

\section{CHOICE OF DATA FOR ANALYSIS}

Changes in health and pollution were studied over each year of the study: 1973-4, 1974-5, 1975-6, and 1976-7. Changes in health and pollution were the only changes considered in the analyses.

Although respiratory illness has been shown cross-sectionally to be associated with the younger age groups, those from the manual social classes, and from homes with gas cookers, ${ }^{7}$ changes in these variables were not expected to interfere with the results. The children were studied at yearly intervals so the change in age was the same for all participants. Changes in social class and cooking fuel were unrelated to change in the levels of pollution. Changes in health may nevertheless have differed between different age or social class groups so age and social class at the initial examination of each period were included in the analyses presented here. Social class at the second examination was also analysed but it did not give different results. Changes in weather conditions may have interfered with the results but they could not be studied because there were no weather stations in the study areas.

\section{STATISTICAL METHODS}

As most children experienced no respiratory conditions and few experienced a change in their number of conditions over time it would have been inappropriate to compare the mean change in number of conditions between areas. Instead, the proportions of children who experienced a decrease, no change, or an increase were studied. Initially the $\chi^{2}$ test for analysis of contingency tables, ${ }^{8}$ in which one classification, either rows or column, is quantitative, was used to test for a trend in proportions across the areas grouped according to their change in levels of pollution. Regression analyses were then conducted to allow for the effects of interfering variables. This analysis used a binary response as the dependent variable. ${ }^{9}$ Further details of this method can be found in the preceding paper. ${ }^{4}$

\section{Results}

\section{RESPONSE RATES}

The response rates are summarised for each period of investigation in Table 1. Most of the exclusions in each period were made because areas had data missing on winter mean levels of pollution. Further exclusions were made if information was missing on ethnic group, if the children lay outside the age range 6 to 11 , or if the children belonged to a non-white ethnic group. Non-white children may have differed from white children in their experience of illness and home environment and there were too few non-whites for separate analysis. Finally, children were omitted from the analyses if they had information missing on the six respiratory conditions reported at each examination or father's social class reported at the initial examination. Among 6-11-year-olds of white ethnic origin eligible for analysis from areas with data on pollution, 857 (73.5\% of 1166 ) were studied during $1973-4,1436$ $(64.7 \%$ of 2219$)$ during $1974-5,2702(66.6 \%$ of $4056)$ during $1975-6$, and $2036(70 \cdot 3 \%$ of 2897$)$ during 1976-7.

LEVELS OF POLLUTION

Initially we examined the levels of pollution and their

Table 1 Summary of the response in each period of investigation

\begin{tabular}{|c|c|c|c|c|}
\hline Response & $1973-4$ & $1974-5$ & $1975-6$ & $1976-7$ \\
\hline $\begin{array}{l}\text { Children in } \\
\text { lst year }\end{array}$ & 8351 & 8503 & 8335 & 8151 \\
\hline $\begin{array}{l}\text { Children in } \\
\text { 2nd year }\end{array}$ & 5686 & 6508 & 6339 & 4281 \\
\hline $\begin{array}{l}\text { Children with } \\
\text { pollution data }\end{array}$ & 1227 & 2326 & 4259 & 3059 \\
\hline \multicolumn{5}{|l|}{ Children excluded because: } \\
\hline Ethnic group not known & 18 & 29 & 59 & 20 \\
\hline Ethnic group non-white & 6 & 20 & 23 & 36 \\
\hline Age outside range 6 to 11 & 37 & 58 & 121 & 106 \\
\hline Incomplete replies & 211 & 534 & 986 & 617 \\
\hline No social class & 98 & 249 & 368 & 244 \\
\hline CHILDREN ANALYSED & D 857 & 1436 & 2702 & 2036 \\
\hline
\end{tabular}


changes in each study period. The levels of pollution were highest and showed the greatest decline in 1973-4 (Table 2). The levels continued to decline in most areas in 1974-5 but by 1975-6 the majority of areas experienced little change in their levels of smoke and $\mathrm{SO}_{2}$. The levels remained low in 1976-7 but the levels of $\mathrm{SO}_{2}$ increased slightly in several areas. It was possible that changes at high levels were more likely to affect health than changes at low levels, so the mean levels for the two winters over which changes were studied were examined in later analyses.

In 1973-4 there was a high negative correlation between the mean level of each pollutant and its change in level (for both pollutants $r=-0.99$, $\mathrm{p}<0.01)$ as the decrease in levels occurred at high levels and no change took place in areas with low levels. In later periods there was no significant correlation between the mean level of each pollutant and its change in level.

CHANGES IN HEALTH AND POLLUTION Simple contingency tables were first used to examine the relation between changes in health and levels of pollution. In 1973-4 no relation was found between changes in health among boys and changes in the levels of smoke $(p>0 \cdot 10)$ but among girls a trend was found contrary to that expected $(p<0 \cdot 10$, Table $3)$. Relatively more girls experienced a decrease than an increase in number of respiratory conditions in areas where there had been little change than in areas where there had been a decrease in levels of smoke. Similar results were found for areas ranked according to their change in levels of $\mathrm{SO}_{2}$.

In subsequent years (Tables 4 to 6 ) no relation was found for either sex between changes in health and changes in the levels of smoke $(p>0 \cdot 10)$ when the proportions who experienced a decrease, no change, or an increase in number of conditions were compared between the areas grouped according to their changes in levels of smoke. In each table the definitions of a decrease, little change, or an increase in the level of pollution were chosen so that the number of areas which fell into each group were similar. In contingency tables for 1974-5 the change in level was combined with the mean level for the two winters because it was possible that a change in health might more readily have occurred in areas with high decreasing levels of pollution than in areas with

Table 2 Summary of winter mean levels of pollution and their changes in each period of investigation

\begin{tabular}{|c|c|c|c|c|c|}
\hline & \multirow[b]{2}{*}{ No. of areas } & \multicolumn{4}{|c|}{ Description of data on pollution $\left(\mu \mathrm{g} / \mathrm{m}^{3}\right)$} \\
\hline & & Pollutant & $\begin{array}{l}\text { Range of } \\
\text { mean levels* }\end{array}$ & $\begin{array}{l}\text { Range of } \\
\text { change in levels }\end{array}$ & Mean change \\
\hline $1973-4$ & 5 & $\begin{array}{l}\text { Smoke } \\
\mathrm{SO}_{2}\end{array}$ & $\begin{array}{l}9.1 \text { to } 113.4 \\
8.1 \text { to } 156.5\end{array}$ & $\begin{array}{l}-58.9 \text { to } 0.0 \\
-93.5 \text { to } 0.0\end{array}$ & $\begin{array}{l}-29 \cdot 2 \\
-43 \cdot 2\end{array}$ \\
\hline $1974-5$ & 9 & $\begin{array}{l}\text { Smoke } \\
\mathrm{SO}_{2}\end{array}$ & $\begin{array}{l}10.9 \text { to } 78.2 \\
13.4 \text { to } 123.7\end{array}$ & $\begin{array}{l}-25.0 \text { to } 3.6 \\
-33.2 \text { to } 20.5\end{array}$ & $\begin{array}{l}-7.1 \\
-5.9\end{array}$ \\
\hline $1975-6$ & 17 & $\begin{array}{l}\text { Smoke } \\
\mathrm{SO}_{2}\end{array}$ & $\begin{array}{r}7.5 \text { to } 76.3 \\
28.6 \text { to } 120.9\end{array}$ & $\begin{array}{l}-29.8 \text { to } 12.2 \\
-49.1 \text { to } 31.0\end{array}$ & $\begin{array}{l}2.0 \\
1.9\end{array}$ \\
\hline $1976-7$ & 14 & $\begin{array}{l}\text { Smoke } \\
\mathrm{SO}_{2}\end{array}$ & $\begin{array}{l}0.0 \text { to } 85 \cdot 8 \\
23.0 \text { to } 120.4\end{array}$ & $\begin{array}{l}-8.9 \text { to } 22.5 \\
-12.8 \text { to } 31.6\end{array}$ & $\begin{array}{r}2 \cdot 8 \\
10 \cdot 0\end{array}$ \\
\hline
\end{tabular}

*The mean of the two winter means in the period under investigation.

Table 3 1973-4 longitudinal analysis. Percentages of boys and girls who experienced a decrease, no change, or an increase in their number of respiratory conditions by amount of decrease in winter mean level of smoke in each area

\begin{tabular}{|c|c|c|c|c|c|c|}
\hline \multirow{2}{*}{$\begin{array}{l}\text { Change in no. of } \\
\text { respiratory conditions }\end{array}$} & \multicolumn{5}{|c|}{ Decrease in winter mean level of smoke $\left(\mu \mathrm{g} / \mathrm{m}^{3}\right)$} & \multirow{2}{*}{$\begin{array}{l}\text { Probability value for } \\
\chi_{1}^{2} \text { for trend }\end{array}$} \\
\hline & $58 \cdot 9$ & $49 \cdot 8$ & $35 \cdot 9$ & $1 \cdot 4$ & 0.0 & \\
\hline \multicolumn{7}{|c|}{ BOYS } \\
\hline $\begin{array}{l}\text { Decrease } \\
\text { No change } \\
\text { Increase }\end{array}$ & $\begin{array}{l}16 \cdot 6 \\
65 \cdot 1 \\
18 \cdot 3\end{array}$ & $\begin{array}{l}21 \cdot 2 \\
65 \cdot 4 \\
14 \cdot 4\end{array}$ & $\begin{array}{l}14 \cdot 3 \\
71 \cdot 4 \\
14 \cdot 3\end{array}$ & $\begin{array}{l}11 \cdot 2 \\
77 \cdot 8 \\
11 \cdot 0\end{array}$ & $\begin{array}{r}13 \cdot 5 \\
81 \cdot 2 \\
5 \cdot 3\end{array}$ & $p>0 \cdot 10$ \\
\hline TOTAL & $\begin{array}{l}100 \\
(109)^{*}\end{array}$ & $\begin{array}{l}100 \\
(52)\end{array}$ & $\begin{array}{l}100 \\
(91)\end{array}$ & $\begin{array}{l}100 \\
(54)\end{array}$ & $\begin{array}{l}100 \\
(133)\end{array}$ & \\
\hline
\end{tabular}

\begin{tabular}{lccccc} 
& \multicolumn{5}{c}{ GIRLS } \\
Decrease & $15 \cdot 3$ & $11 \cdot 1$ & $13 \cdot 8$ & $27 \cdot 3$ & $12 \cdot 9$ \\
No change & $67 \cdot 6$ & $73 \cdot 0$ & $63 \cdot 1$ & $67 \cdot 3$ & $76 \cdot 6$ \\
Increase & $17 \cdot 1$ & $15 \cdot 9$ & $23 \cdot 1$ & $5 \cdot 4$ & $10 \cdot 5$ \\
TOTAL & 100 & 100 & 100 & 100 & 100 \\
& $(111)$ & $(63)$ & $(65)$ & $(55)$ & $(124)$ \\
\hline
\end{tabular}

*Total no. of children in brackets. 
medium or low decreasing levels. Changes in health in the three one-year periods between 1974 and 1977 were also unrelated to changes in the levels of $\mathrm{SO}_{2}$ in similar analyses.

A more detailed examination of the relation between changes in health and pollution was conducted in regression analyses in which continuous measures of pollution were used. In addition to pollution, age and social class were included in the analyses because these have consistently been found to be related to respiratory illness in cross-sectional studies. Values of age and social class were taken from the examination at the beginning of each study period.

In each period age and social class showed no consistent or statistically significant relation to change in health. In 1973-4 improvement in health after allowing for the effects of the other variables was associated with low levels of pollution which showed little change $(p<0.05)$. In 1974-5 no relation was found in boys between improvement in health and changes in the levels of smoke or $\mathrm{SO}_{2}$ $(p>0 \cdot 10)$ but in girls a relation was found between change in health and changes in the levels of smoke which depended on the levels at which the changes occurred $(p<0.05)$. Within the most polluted areas improvement in health seemed to be associated with levels of smoke which showed little change or slight increases contrary to expectation, and within the least polluted areas little association was found between improvement in health and changes in the levels. In 1975-6 and 1976-7 improvement in health in both sexes was unrelated to changes in the levels of

Table 4 1974-5 longitudinal analysis. Percentages of boys and girls who experienced a decrease, no change, or an increase in their number of respiratory conditions by areas grouped according to their changes in winter mean level of smoke

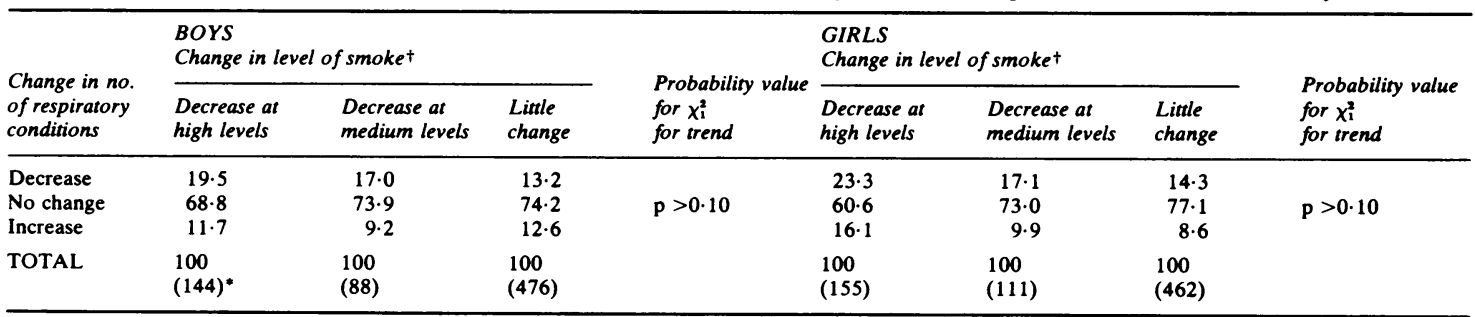

† Decrease: $\quad<10 \mu \mathrm{g} / \mathrm{m}^{2}$

Little change: $>10<5 \mu \mathrm{g} / \mathrm{m}^{3}$

High level: $>40 \mu \mathrm{g} / \mathrm{m}^{3}$

Medium level: 25 to $40 \mu \mathrm{g} / \mathrm{m}^{3}$

*Total no. of children in brackets

Table 5 1975-6 longitudinal analysis. Percentages of boys and girls who experienced a decrease, no change, or an increase in their number of respiratory conditions by areas grouped according to their change in winter mean level of smoke

\begin{tabular}{|c|c|c|c|c|c|c|c|c|}
\hline \multirow{2}{*}{$\begin{array}{l}\text { Change in no. } \\
\text { of respiratory } \\
\text { conditions }\end{array}$} & \multicolumn{3}{|l|}{ BOYS } & \multirow{2}{*}{$\begin{array}{l}\text { Probability } \\
\text { value for } \chi_{1}^{2} \\
\text { for trend }\end{array}$} & \multicolumn{3}{|c|}{ GIRLS } & \multirow{2}{*}{$\begin{array}{l}\text { Probability } \\
\text { value for } \chi_{1}^{2} \\
\text { for trend }\end{array}$} \\
\hline & \multicolumn{3}{|c|}{ Change in level of smoke $\left(\mu \mathrm{g} / \mathrm{m}^{3}\right)$} & & \multicolumn{3}{|c|}{ Change in level of smoke $\left(\mu g / m^{2}\right)$} & \\
\hline $\begin{array}{l}\text { Decrease } \\
\text { No change } \\
\text { Increase }\end{array}$ & $\begin{array}{r}10.9 \\
79.7 \\
9.4\end{array}$ & $\begin{array}{r}14 \cdot 3 \\
76 \cdot 8 \\
8 \cdot 9\end{array}$ & $\begin{array}{r}16 \cdot 5 \\
75 \cdot 9 \\
7.6\end{array}$ & $p>0 \cdot 10$ & $\begin{array}{r}11 \cdot 3 \\
80 \cdot 2 \\
8 \cdot 5\end{array}$ & $\begin{array}{r}10 \cdot 2 \\
81 \cdot 3 \\
8 \cdot 5\end{array}$ & $\begin{array}{r}13 \cdot 7 \\
78 \cdot 6 \\
7 \cdot 7\end{array}$ & $p>0 \cdot 10$ \\
\hline TOTAL & $\begin{array}{l}100 \\
(256)^{*}\end{array}$ & $\begin{array}{l}100 \\
(349)\end{array}$ & $\begin{array}{l}100 \\
(726)\end{array}$ & & $\begin{array}{l}100 \\
(248)\end{array}$ & $\begin{array}{l}100 \\
(342)\end{array}$ & $\begin{array}{l}100 \\
(781)\end{array}$ & \\
\hline
\end{tabular}

*Total no. of children in brackets

Table 6 1976-7 longitudinal analysis. Percentages of boys and girls who experienced a decrease, no change, or an increase in their number of respiratory conditions by areas grouped according to their change in winter mean level of smoke

\begin{tabular}{|c|c|c|c|c|c|c|c|c|}
\hline \multirow{2}{*}{$\begin{array}{l}\text { Change in no. } \\
\text { of respiratory } \\
\text { conditions }\end{array}$} & \multicolumn{3}{|l|}{ BOYS } & \multirow{2}{*}{$\begin{array}{l}\text { Probability } \\
\text { value for } \chi_{1}^{2} \\
\text { for trends }\end{array}$} & \multicolumn{3}{|c|}{ GIRLS } & \multirow{2}{*}{$\begin{array}{l}\text { Probability } \\
\text { value for } \chi_{1}^{2} \\
\text { for trend }\end{array}$} \\
\hline & \multicolumn{3}{|c|}{ Change in level of smoke $\left(\mu \mathrm{g} / \mathrm{m}^{3}\right)$} & & \multicolumn{3}{|c|}{ Change in level of smoke $\left(\mu \mathrm{g} / \mathrm{m}^{3}\right)$} & \\
\hline $\begin{array}{l}\text { Decrease } \\
\text { No change } \\
\text { Increase }\end{array}$ & $\begin{array}{l}15 \cdot 3 \\
71 \cdot 4 \\
13 \cdot 3\end{array}$ & $\begin{array}{r}11 \cdot 9 \\
78 \cdot 7 \\
9 \cdot 4\end{array}$ & $\begin{array}{r}14 \cdot 9 \\
76 \cdot 3 \\
8 \cdot 8\end{array}$ & $p>0 \cdot 10$ & $\begin{array}{l}16 \cdot 7 \\
70 \cdot 1 \\
13 \cdot 2\end{array}$ & $\begin{array}{r}12.6 \\
80 \cdot 4 \\
7 \cdot 0\end{array}$ & $\begin{array}{r}16 \cdot 0 \\
76 \cdot 1 \\
7 \cdot 9\end{array}$ & $p>0 \cdot 10$ \\
\hline TOTAL & $\begin{array}{l}100 \\
(189)^{*}\end{array}$ & $\begin{array}{l}100 \\
(595)\end{array}$ & $\begin{array}{l}100 \\
(215)\end{array}$ & & $\begin{array}{l}100 \\
(197)\end{array}$ & $\begin{array}{l}100 \\
(602)\end{array}$ & $\begin{array}{l}100 \\
(238)\end{array}$ & \\
\hline
\end{tabular}

*Total no. of children in brackets 
pollution $(p>0 \cdot 10)$. It was possible in each period that an association between improvement in health and decreasing levels of pollution might more readily have been found in subgroups of children who were particularly susceptible to respiratory illness, such as those from the young age groups or manual classes. However, no association was found within these groups.

The measure of improvement in health did not take into account the initial number of respiratory conditions experienced by each child and it was possible that children with severe respiratory illness might have been more susceptible than others to effects from changes in pollution. In the cross-sectional analyses greater frequency of severe illness, defined as the presence of three or more respiratory conditions, was associated with high levels of smoke. In additional longitudinal analyses, improvement and deterioration in health were studied by examining the proportions of children who changed from having severe to less severe illness and less severe to severe illness respectively. The number of children in each area who fell into these categories was very small, rarely more than 10 , so the analyses were very limited. However, this measure of change in health was also unrelated to changes in the levels of pollution in the same way as the change in number of conditions which was first used.

Finally, we investigated the possibility that changes in health over more than one year might be related more closely to changes in the levels of pollution than health measured over only one year. However, between 1973 and 1975, when large decreases in levels of pollution occurred, no relation was found.

\section{Discussion}

Throughout the period of the study no consistent relation was found between change in health and changes in the levels of pollution. Over the period when the levels of pollution were highest and showed the greatest decline, relatively more children experienced a decrease than an increase in their respiratory conditions in areas with low unchanging levels of pollution than in areas with high decreasing levels, contrary to the expected trend. It could be argued that the high levels had not declined enough and children remained at greater risk from illness in the polluted than the non-polluted areas. If this were true, improvement in health should have been associated with decreasing low levels of pollution which occurred in subsequent years, but this was not the case.

Therefore the association between improvement in health and decreasing levels of pollution in 1973-4 seems more likely to have been determined by some factor other than pollution, such as weather conditions. The polluted areas of the study were found in the north, where temperatures tend to be colder than in the south, and low temperatures have been associated with a high incidence of respiratory disease.$^{10}$ Thus children living in the north may have been at greater risk from developing respiratory illness than those in the south.

Alternatively, it might be argued that no relation could be found between change in health and changes in the levels of pollution because the former was an inappropriate or imprecise measurement. However, in the cross-sectional analyses a count of the number of respiratory conditions reported each year provided a measure of illness which was found to be related to the levels of smoke in the study areas. In the longitudinal analyses the change from one group of conditions to another might have been studied but it would have been difficult to interpret.

Further evidence that changes in the levels of pollution did not affect health comes from the analysis of children who were thought to be particularly susceptible to respiratory illness. No relation was found between health and changes in the levels among the younger age groups, the manual social classes, or those with severe illness.

The effects on health from annual changes in the levels of pollution seem to have been investigated in few studies. In one study ${ }^{211}$ a cohort of children living in Sheffield were examined when they reached the age of 5 during 1963-5 and then four years later at the age of 9 . In contrast to the national study, only cross-sectional analyses were performed, but as the areas were located within one city regional differences such as annual weather conditions would not have interfered with the results. It seems likely that the decline in levels of pollution which occurred from 1964 to 1968 contributed to the disappearance of a difference in prevalence rates of respiratory illness between areas. However, the rates were associated with past episodes of illness ${ }^{11}$ so the decline in levels of pollution before as well as during the study may have caused improvement in health. No information on previous levels was provided but even those during 1964-8 were well above the levels in the national study.

In another study from Sheffield, changes in the health of adults with established airways obstruction appeared to be associated with the decline in levels of pollution. ${ }^{12}$ The rate of decline of forced expiratory volume in patients followed during 1966-72 was only one-third of the rate of decline in patients of the same age studied during 1960-5. The prevalence rates of respiratory symptoms and illnesses were also lower in the former than the latter group. Improvement in the health of the patients occurred during a period when the levels of atmospheric smoke and $\mathrm{SO}_{2}$ were 
declining markedly as described for the previous study.

Changes in the health of patients with chronic respiratory disease were studied in greater detail in London between 1954 and $1968 .{ }^{13}$ Daily changes in health were recorded by the patients and compared with daily measures of smoke and $\mathrm{SO}_{2}$. Deterioration in health was associated with high peak levels of smoke and $\mathrm{SO}_{2}$ but as the annual levels of pollution declined, the number of days with high peak levels became infrequent, and the correlation between changes in health and changes in the levels of pollution became small and statistically non-signifcant. Comparison of results from this study and the national study is limited because the former study was concerned with daily changes and the latter with annual changes. However, the decline in the number of days with peak levels of pollution in London which was related to deterioration in health was associated with a decline in annual means well above those in the national study. Only the levels in the last year of the study in London, 1967-8, were similar to those in the national study.

In conclusion, the evidence suggests that the levels of pollution measured during the national study were not harmful to health. Thus the cross-sectional finding of an association between respiratory illness and levels of smoke reported in the previous paper is unlikely to be causative. The results clearly throw doubt on the interpretation of many cross-sectional studies of air pollution and on air quality standards ${ }^{1415}$ which have been based on cross-sectional results.

The study was supported by a grant from the Department of Health and Social Security. The authors are grateful to Professor Holland, Dr. Leslie Irwig, Mr. Douglas Altman and Ms. Lol Ide. We acknowledge the assistance of staff from the area health authorities, the children's schools, and environmental and public health departments. Members of Warren Spring Laboratory, Stevenage, assisted in the siting of the pollution monitoring stations, processed the data on smoke and $\mathrm{SO}_{2}$ and helped us to maintain quality of the data throughout the study.
Reprints from Dr. R. J. W. Melia, Department of Community Medicine, St. Thomas's Hospital Medical School, London, SE1 7EH.

\section{References}

${ }^{1}$ Douglas JWB, Waller RE. Air pollution and respiratory infection in children. Br J Prev Soc Med 1966; 20: 1-8.

${ }^{2}$ Lunn JE, Knowelden J, Handyside AJ. Patterns of respiratory illness in Sheffield infant schoolchildren. $\mathrm{Br}$ J Prev Soc Med 1967; 21: 7-16.

${ }^{3}$ Weatherley M-L PM, Gooriah BD, Charnock J. Fuel consumption, smoke and sulphur dioxide. Emissions and concentrations, and grit and dust deposition in the $U K$, up to 1973-4. LR $214(A P)$. Stevenage: Warren Spring Laboratory, 1976.

4Melia RJW, Florey C du V, Swan AV. Respiratory illness in British schoolchildren and atmospheric smoke and sulphur dioxide 1973-7. 1: Cross-sectional findings. J Epidemiol Community Health 1981; 35: 161-7.

${ }^{5}$ Warren Spring Laboratory. National Survey of Smoke and Sulphur Dioxide Instruction Manual. Stevenage: Warren Spring Laboratory, 1966.

${ }^{6}$ Korn EL, Whittemore AS. Methods for analyzing panel studies of acute health effects of air pollution. Biometrics 1979; 35: 795-802.

${ }^{7}$ Melia RJW, Florey C du V, Chinn S. The relation between respiratory illness in primary schoolchildren and the use of gas for cooking. I-Results from a National Study. Int J epidemiol 1979; 8: 333-8.

${ }^{8}$ Yates $F$. The analysis of contingency tables with groupings based on quantitative characters. Biometrika 1948; 35: 176-81.

${ }^{9}$ Dyke SV, Patterson HD. Analysis of factorial arrangements when the data are proportions. Biometrics 1952; 8: 1-12.

${ }^{10}$ Holland WW, Spicer CC. Influence of weather on respiratory disease. Biometrics 1966; 2: 30-40.

${ }^{11}$ Lunn JE, Knowelden J, Roe JW. Patterns of respiratory illness in Sheffield junior schoolchildren. Br J Prev Soc Med 1970; 24: 223-8.

${ }^{12}$ Howard $P$. The changing face of chronic bronchitis with airways obstruction. $\mathrm{Br}$ Med J 1974; ii: 89-93.

${ }^{13}$ Lawther PJ, Waller RE, Henderson M. Air pollution and exacerbations of bronchitis. Thorax 1970; 25: 525-39.

${ }^{14}$ Biersteker K. Sulfur dioxide and suspended particulate matter. Where do we stand? Environ Res 1976; ii: 287-304.

${ }^{15}$ World Health Organisation. Environmental Health Criteria 8. Sulfur Oxides and Suspended Particulate Matter. Geneva: WHO, 1979. 